\title{
BECOOL: A BALLOON-BORNE MICROLIDAR SYSTEM DESIGNED FOR CIRRUS AND CONVECTIVE OVERSHOOT MONITORING
}

\author{
François Ravetta $^{1 *}$, Vincent Mariage ${ }^{1}$, Emmanuel Brousse $^{1}$, Eric d'Almeida $^{1}$, Frédéric Ferreira $^{1}$, \\ Jacques Pelon ${ }^{1}$, Stéphane Victori ${ }^{2}$ \\ ${ }^{1}$ Laboratoire Atmosphère Milieux, Observations Spatiales (LATMOS), CNRS-INSU, Sorbonne \\ Université,Université Versailles St Quentin, Paris, France \\ ${ }^{2}$ Cimel Electronique, Paris, France \\ *Email: francois.ravetta@latmos.ipsl.fr
}

\begin{abstract}
A balloon-borne microlidar has been built at LATMOS to monitor cirrus optical properties and convective overshoot topography during long duration flights in the lower tropical stratosphere. Weighting less than $7 \mathrm{~kg}$ in a reduced volume and consuming less than $10 \mathrm{~W}$, it will be involved in the CNES-Strateole2 campaign. This instrument paves the way to the use of microlidar technology for planetary missions.
\end{abstract}

\section{Scientific context and objectives}

The CNES project Strateole2 aims at flying different configurations of multi instrumented open stratospheric balloons (OSB) in the lower tropical stratosphere to study the tropical tropopause layer (TTL). Long duration (several months) flights are planned to improve our knowledge of air-masses transport and dehydration processes. Relationship between temperature anomaly and cirrus occurrence has already been highlighted thanks to the Airborne Tropical TRopopause EXperiment (ATTREX) NASA campaign [1], with the Cloud Physics Lidar [2] onboard an unmaned aircraft system. The BeCOOL (Balloonborne Cirrus and convective overshOOt Lidar) system was conceived to be one of the payloads of the OSB configurations (see Fig.1). This profiler will measure optical properties of cirrus in nadir viewing mode and characterize the upper topography of convective system. The payload of the flight configuration also involves a GPS radiooccultation [3] to reveal temperature anomalies and a bolometer [4] to measure upward longwave and shortwave radiative fluxes. The goal is to better understand modulation of cirrus properties by gravity waves [5], and to better assess the radiative heating [6] and forcing [7] of the lower stratosphere by cirrus and water vapor anomalies.

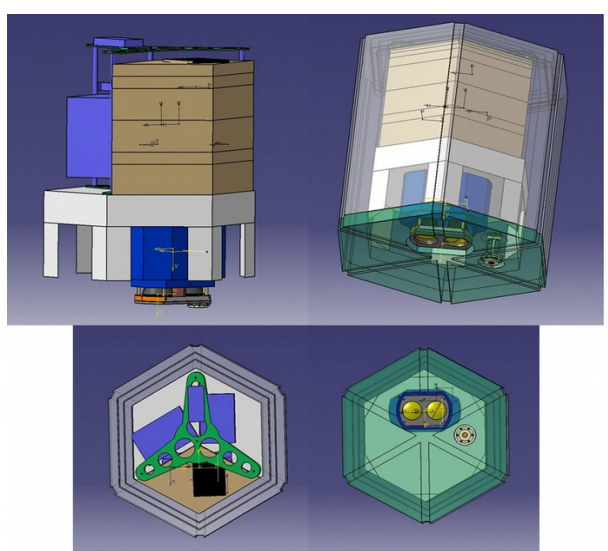

Fig. $13 \mathrm{D}$ drawing of the BeCOOL microlidar in the STRAT configuration gondola. The insulated hexagonal shaped boxes used to contain parts of the instrument are shown in brown. They are located in the same volume as the batteries and other instruments. The telescope with its two lenses can be seen in the lower "cold" volume of the gondola.

\section{Instrumental development}

The BeCOOL system is based on the biaxial microlidar architecture developed for the French Ice Atmosphere Arctic Ocean Observing System (IAOOS project) which aimed at deploying a network of multi-instrumented buoys in the Arctic region [8]. Its main characteristics (see Tab.1) are comparable to those of balloon-borne microjoule lidars first developed [9]. The use of optical fibers between the components of the microlidar eases the integration of the system, particularly to separate the telescope (located in the "cold" area of the gondola) and the thermally sensitive parts. A specific laser driver board and an onboard computer were developed by Cimel Electonique, respectively to handle the supply of the laser diode as well as its thermal regulation, and to deal 
with data acquirement and communication with the gondola. Given the balloon-borne constraints and stratospheric environment, a solution had to be found to put all the components in a very small volume. An appropriate insulation is made for the thermally sensitive parts like the laser diode and the interferential filter. The telescope is placed apart and operated in external air conditions. The weight was also decreased by removing some parts of the IAOOS telescope and using lighter materials. Numerous tests were performed in a test chamber at very low temperatures and low pressure to ensure a proper behaviour of all the components. The thermal regulation of the laser diode is particularly difficult to handle because of the lack of convection in the OSB.

\begin{tabular}{|l|l|}
\hline $\begin{array}{l}\text { Repetition } \\
\text { rate/impulsion length }\end{array}$ & $4.8 \mathrm{kHz} / 150 \mathrm{~ns}$ \\
\hline Wavelength/FWHM & $\sim 802 \mathrm{~nm} / \sim 0.3 \mathrm{~nm}$ \\
\hline Impulse energy & $10 \mu \mathrm{J}$ \\
\hline $\begin{array}{l}\text { Lens diameter } \\
\text { (emission/reception) }\end{array}$ & $7 \mathrm{~cm}$ \\
\hline FOV & $650 \mu \mathrm{rad}$ \\
\hline Filter FWHM & $0.6 \mathrm{~nm}$ \\
\hline $\begin{array}{l}\text { Optical transmission } \\
\text { (receiver) }\end{array}$ & $10-15 \%$ \\
\hline Total mass & $<7 \mathrm{~kg}$ \\
\hline Average power supply & $<10 \mathrm{~W}$ \\
\hline
\end{tabular}

Tab.1 Main characteristics of the balloon-borne lidar BeCOOL

\section{First balloon-borne measurements}

A first flight was successfully achieved within the STRATOSCIENCE campaign in August 2018, at Timmins, Canada. Flying at an altitude of 22 kilometers, the lidar has demonstrated its ability to observe cirrus at the tropopause and aerosol in the boundary layer during nighttime (see Fig. 2). The SNR is seen to decrease with the sunrise at the end of the flight, but cirrus are still well captured. The increase of SNR during the first 30 minutes is due to the self-heating of the laser diode emitting continuously.

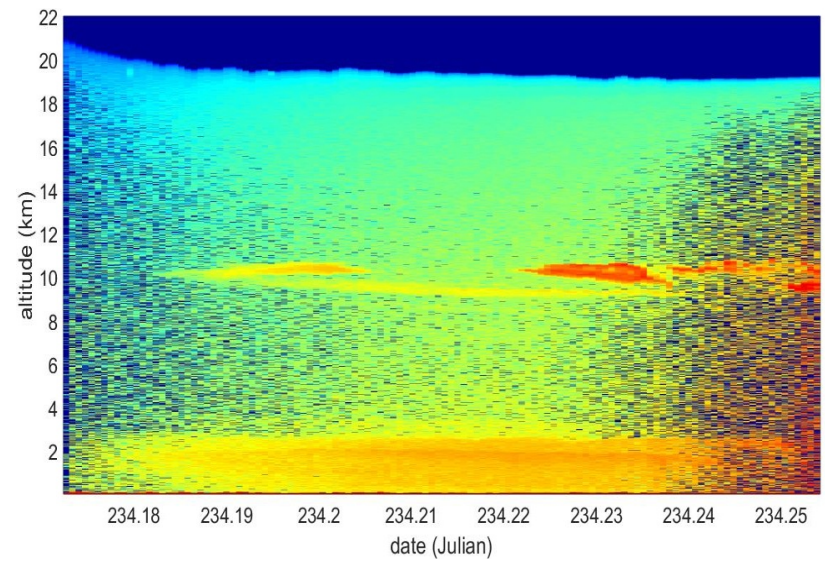

Fig. 2 Vertical cross section of the range-corrected attenuated backscattered signal (arbitrary unit) averaged over one minute for a leg of 2 hours LT on August 23 2018.

\section{Conclusion and Perspectives.}

The first Strateole2 field campaign will take place in winter 2019-2020. Beyond the scientific objectives of this CNES program, the development of this balloon-borne system is also an opportunity to increase the technology readiness level (TRL) of the microlidar technology so that, with further instrumental improvements, it may be implemented onboard a planetary rover or a small satellite.

\section{Acknowledgments}

We thank the French Centre National d'Etudes Spatiales (CNES) for its support to the Strateole2 program, the Canadian Space Agency for the flight at Timmins, Sylvain Meunier and Joseph Leclercq from Cimel for their contribution.

\section{REFERENCES}

[1] E. J. Jensen et al, Bull. AMS, 129-143 (2017)

[2] M. McGill et al., Appl. Opt.,(41) 3725-3734 (2002)

[3] J. S. Haase et al., Geophys. Res.L., 39, (2012)

[4] P. Zhu et al., Geos. Inst. Meth. and Data Systems, 89-98, (2015)

[5] J.-E. Kim et al, Geophys. Res. L. (43), 5895-5901

(2016)

[6] S. Davis et al., J.Geophys Res, 115 (2010)

[7] S. Solomon et al., Science (327), 1219-1223 (2010)

[8] V. Mariage et al., Optics Express 25 (4), A73-A84

(2017)

[9] G. Di Donfrancesco et al., Appl. Opt. (45) 57015708 (2006) 